\title{
Research on Gold Contact Materials
}

\author{
A REVIEW OF THE HOLM SEMINAR AND THE \\ INTERNATIONAL CONTACT CONFERENCE
}

\author{
Morton Antler \\ Bell Telephone Laboratories, Inc., Columbus, Ohio, U.S.A.
}

\begin{abstract}
The year 1976 was eventful in this field, with significant new work appearing on gold contacts, both wrought and electroplated, for connectors, printed circuit boards, sealed relays and instrument slip rings. The Holm Seminars on Electrical Contacts in Chicago and the International Conferences on Electrical Contact Phenomena, on this occasion held in Tokyo, continue as major meetings for workers in this field. The papers reviewed represent the range of work that is being done with gold; the first two papers were presented at the Holm Seminar; these are followed by two from the International Conference.
\end{abstract}

For engineers and physicists concerned with the behaviour and reliability of electrical contacts these two conferences provided some most useful information and presented opportunities for valuable discussions in a number of fields in which gold or its alloys play an important part.

\section{Alloy Gold Slip Rings}

Contact resistance stability is a requirement of instrument slip rings, and one of the most stringent methods of operation involves oscillation over small angles for a large number of cycles with occasional excursions over larger angles. The degrading influences of system outgas products and of wear debris are maximised in this way. S. R. Cole, B. K. Witherspoon, C. W. Reed, and N. E. Lewis of Poly-Scientific, Litton Systems, Blacksburg, Virginia, found contact resistance noise and alloy gold content to be inversely related in "A Test of Noble Metal Slip Ring Alloys for Use in Inertial Guidance Platforms". Sliding was in nitrogen or in a mixed atmosphere containing several dozen organic compounds with varied molecular weights in the range 10 to $1000 \mathrm{ppm}(\mathrm{v} / \mathrm{v})$. Brush material was 71.5 Au-15.5 Cu-8.5 Pt-4.5 Ag-1 Zn (ASTM B541), contact load was $3 \mathrm{~g}$, and the rings were lubricated.

The alloys, grouped in order of noise performance, from good to poor, were: Group I-75 Au-22 Ag$3 \mathrm{Ni}$ (ASTM B477), $96 \mathrm{Au}-4 \mathrm{Ni}, 99 \mathrm{Au}-1 \mathrm{Ni}$ electrodeposit; Group II-ASTM B541, 10 Cd-90 Au; Group III-54.5 Au-37.5 Ag-4 Cd-4 In. Although the wear rates of the ring materials were comparable, prows of transferred material on the brush were primarily responsible for the noise. It is not surprising that the more noble metals proved superior, because the prows were accretions of finely divided ring material, and the amounts of oxide films on these particles were expected to follow closely their base metal contents.

\section{Corrosion Resistance of Gold Plated Tin-Nickel}

Thin gold platings on tin-nickel underplate are remarkably corrosion resistant, according to $M$. Antler and M. Feder, Bell Laboratories, Columbus, Ohio, and C. F. Hornig and J. Bohland of Western Electric, N. Andover, Massachusetts, in "The Corrosion Behaviour of Single and Multiphase Tin-Nickel Alloy Electrodeposits". The wellknown chemical stability of tin-nickel having the approximate composition 65 tin-35 nickel ( $1: 1$ atom ratio) is due to a protective oxide which is responsible also for its unacceptably high contact resistance. Because of interest in materials conservation and cost reduction for electrical contacts, gold platings of reduced thickness are attractive, but, if porous, corrosion may occur in polluted atmospheres when the deposit is on copper, nickel and many other substrates. A galvanic couple, however, does not persist with porous gold on tin-nickel because of the passivity that arises on exposure to air-provided that the tin-nickel layer is free from porosity and other defects such as cracks produced by deformation of the surface. This finish has been used for the edge contacts of copper-clad laminate printed circuit boards where it also serves as an etch resist. 
This investigation was made with 0.5 micrometre of a cobalt-hardened gold plating on tin-nickel. Exposures at high relative humidities in the laboratory included $\mathrm{NO}_{2}, \mathrm{SO}_{2}, \mathrm{H}_{2} \mathrm{~S}, \mathrm{NH}_{3}, \mathrm{Cl}_{2}$, sulphur vapour, salt spray, a synthetic dust, and mixtures of some of the gases. The contact surfaces remained free of films, according to visual observations and contact resistance determinations. The thickness of gold specified for contacts need no longer depend on porosity-corrosion considerations when tin-nickel can be used as an underplate.

\section{Clad Inlay Gold Connector Contacts}

A new gold alloy with silver and palladium and containing small amounts of tin and indium as hardeners was described at the International Conference by N. Harmsen of W. C. Heraeus, Hanau, West Germany in "Spring-Hard Precious Metal Alloys with Good Tarnishing Behaviour for Electrical Contacts". This material, 51.5 Au-18 Ag-26.5 Pd-4 (Sn+In) is proposed as a contact cladding for connector springs. It combines favourable cost with generally equal or superior properties to older alloys it is intended to replace, such as $70 \mathrm{Au}-20 \mathrm{Ag}-10 \mathrm{Cu}$ and $71 \mathrm{Au}-26 \mathrm{Ag}-3 \mathrm{Ni}$.

The alloys were rolled into sheets with 30 to 50 per cent deformation, and were evaluated for stability of contact resistance with a gold probe in separate screening tests involving heating in air for 1 minute at $250^{\circ} \mathrm{C}$, exposure for 2 days at 75 per cent $\mathrm{RH}$ to $1 \mathrm{ppm} \mathrm{H}_{2} \mathrm{~S}$, or to 10 ppm $\mathrm{SO}_{2}$ in the same conditions. Contact resistance at $5 \mathrm{~g}$ and at $100 \mathrm{~g}$ changed relatively little in these tests, while the $\mathrm{Au}-\mathrm{Ag}-\mathrm{Cu}$ alloy showed significant degradation on heating. Some of the physical properties of the new alloy are: density, 14.3; electrical conductivity, $3.3 / \Omega \mathrm{m}$; Young's modulus, $130 \mathrm{kN} / \mathrm{mm}^{2}$, and, in the age hardened state, hardness $3200 \mathrm{~N} / \mathrm{mm}^{2}$; tensile strength, $1030 \mathrm{~N} / \mathrm{mm}^{2} ; 0.2$ yield strength, 1015 $\mathrm{N} / \mathrm{mm}^{2}$; elongation, 2 per cent.

\section{Basic Studies of Gold Adhesion and Transfer}

A major contact application for gold is in sealed reed relays which are widely used in telecommunications equipment for switching at low current and voltage levels. Electroplated hard gold or plated layers of gold and silver which subsequently are diffused by heating have been eminently successful. Pure gold is not used because of its high sticking tendency. K. Fujiwara and Y. Yamaguchi, in a paper on "Effects of Surface Contamination on Adhesion and Transfer of Gold", shed new light on factors involved in sticking in an elegant study where the effects of surface cleaning and several methods of operating contacts at non-arcing conditions were examined. The authors are with Nippon Telegraph and Telephone, Ibaraki, Japan. This study was with $2 \mathrm{~mm}$ diameter crossed rods of 99.999 per cent solid gold in a vacuum chamber having fixtures for loading, unloading, sliding, and making and breaking contact in simulated device operation, with fittings for heating and for cleaning by argon ion bombardment.

Significant findings were that embedments occurred in the abrasion treatment, identified as $\mathrm{SiO}_{2}$ by ion probe mass analysis and Electron Spectroscopy for Chemical Analysis (ESCA). At $10 \mathrm{~g}$ these particles significantly reduced metal transfer and the coefficient of adhesion (ratio of separation force to normal load). With chemically etched gold, the coefficient of adhesion increased from 0.05 to 0.45 as a result of heating and argon ion bombardment, and subsequent exposure to nitrogen or carbon monoxide, which are constituents of reed relay atmospheres, reduced adhesion with carbon monoxide rather more effective. Although metal transfer, determined by radiotracer analysis, increased from $10^{-10}$ to $10^{-9} \mathrm{~g}$ as a result of ion bombardment, it was not much lowered by the subsequent nitrogen and carbon monoxide exposures.

When the contacts were opened and closed in air, the coefficient of adhesion for any surface treatment increased due to removal of surface contaminations; however, operation at $10^{-9}$ torr after ion bombardment produced a lowering in adhesion, and after 1000 operations it was 0.1 , the same as in air. The decrease is believed due to work hardening of surface asperities whose deformation under load changed from primarily plastic to elastic; elastic recovery reduced adhesion without significantly affecting metal transfer. Transfer increased with numbers of contact operations.

Tangential displacement at $45^{\circ}$ (which brings new surface continuously into contact) and $10^{-8}$ torr increased the coefficient of adhesion significantly in only 1 micrometre with little further increase to 5 micrometres. The coefficient was 2 with heated-ion bombarded contacts and 1 in the absence of ionbombardment. Contact resistance decreased steadily with sliding, from $1.5 \mathrm{~m} \Omega$ initially to $0.7 \mathrm{~m} \Omega$ after 5 micrometres. Tangential displacement in air also increased adhesion, but less markedly than in vacuum except with long slides, to 500 micrometres, where it exceeded 3 with a contact resistance of $0.5 \mathrm{~m} \Omega$. The effect of tangential sliding can be explained by the growth of asperity junctions. The strength of a joint was about equal to the bulk strength of cold worked gold, estimated from the size of the contact using contact resistance theory.

Finally, heating specimens to $350^{\circ} \mathrm{C}$ increased the coefficient of adhesion with lowering in contact resistance. 